\title{
Novel Strategies for Fluorine-18 Radiochemistry
}

\author{
Ryan Littich and Peter J. H. Scott*
}

computed tomography fluorine - imaging - radio-

chemistry $\cdot$ radiopharmaceuticals

$P$ ositron $\left(\beta^{+}\right)$emission tomography (PET) is a powerful, noninvasive tool for the in vivo, three-dimensional imaging of physiological structures and processes. PET imaging involves the incorporation of short-lived radionuclides, particularly carbon- 11 and fluorine- 18 , into biologically active molecules. The resulting radiopharmaceuticals are introduced into human subjects, liberating positrons in the decay process that subsequently annihilate with electrons in adjacent matter. Detection of the $\gamma$ radiation generated during annihilation allows for well-defined images of ongoing bodily processes to be obtained. Understandably, wielding this technologywhich requires the manipulation of strong radioemitters, short end-product efficacy timeframes, and rigorous quality control-is not a simple undertaking. In answer to this, and speaking to its clinical value, research pertaining to PET has observed exciting and rapid growth.

The prospective applications for PET imaging are innumerable. ${ }^{[1]}$ Exploiting PET to its fullest potential has been limited, however, in large part, by the availability of pertinent radiopharmaceuticals. The identification of a suitable radionuclide for use in labeling is a concern intrinsic to the preparation of radiopharmaceutical agents. Carbon-11 and fluorine-18 are commonly used and each has its own merits. Radiolabeling with ${ }^{11} \mathrm{C}$ has advantages that include minimal effects on substrate biological activity and ease of incorporation. ${ }^{11} \mathrm{C}$-radiolabeling also affords the ability to run multiple scans per day in series. However, ${ }^{11} \mathrm{C}$ suffers from a rather short half-life $(20 \mathrm{~min})$ and susceptibility to environmental ${ }^{12} \mathrm{C}$ contamination in processing. ${ }^{[2]}{ }^{18} \mathrm{~F}$ finds utility in light of the fact that its incorporation into bioactive species sometimes affects their pharmacological profile. Fluorine- 18 offers the benefit of a substantial half-life (about 110 min, allowing for distribution to satellite PET scan facilities), a clean decay process $\left(97 \% \beta^{+}\right.$emission) and limited positron migration (about $1 \mathrm{~mm}$, leading to highly resolved images). Indeed, ${ }^{18} \mathrm{~F}$ is ubiquitous in molecular imaging by positron emission tomography, as is exemplified by the success of $\left[{ }^{18} \mathrm{~F}\right] 2$-fluoro2-deoxy-D-glucose (FDG) in oncology research.

$\left[{ }^{18} \mathrm{~F}\right]$ Fluoride is prepared by the proton bombardment of oxygen-18 enriched water through the nuclear reaction ${ }^{18} \mathrm{O}(\mathrm{p}, \mathrm{n}){ }^{18} \mathrm{~F}$. Aqueous solutions of ${ }^{18} \mathrm{~F}^{-}$are rendered, from which the ion of interest can be isolated by ion-exchange

[*] Dr. R. Littich, Dr. P. J. H. Scott

Department of Radiology, University of Michigan Medical School Ann Arbor, MI 48109 (USA)

E-mail: pjhscott@umich.edu chromatography. Gaseous $\left[{ }^{18} \mathrm{~F}\right] \mathrm{F}_{2}$ is also available through the nuclear reaction ${ }^{20} \mathrm{Ne}(\mathrm{d}, \mathrm{a}){ }^{18} \mathrm{~F}$. The former facilitates nucleophilic fluorination reactions; the latter, electrophilic fluorination. Both reaction modes have important applications in PET imaging research. This article discusses recent strides in the field of ${ }^{18} \mathrm{~F}$ radiochemistry, categorized by the reaction motif.

Gouverneur and co-workers recently disclosed the preparation of $\left[{ }^{18} \mathrm{~F}\right]$ Selectfluor bis(triflate) $\mathbf{1}$ as a means to broaden the scope and utility of electrophilic fluorination for ${ }^{18} \mathrm{~F}$ radiochemistry. ${ }^{[3]}$ Inspired by the mild, commercially available fluorinating agent Selectfluor, ${ }^{[4]} 1$ was prepared through chloromethylation of diazabicyclo[2.2.2]octane, anion exchange, and subsequent fluorination using high-specific activity $\left[{ }^{18} \mathrm{~F}\right] \mathrm{F}_{2}$ (Scheme 1$)$. The resulting bis(triflate) was

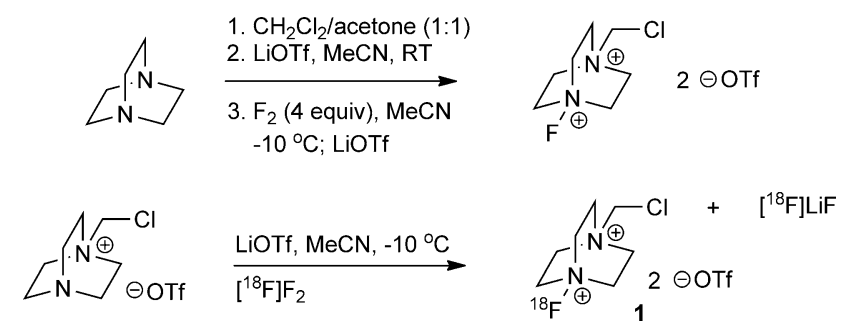

Scheme 1. Synthesis of $\left[{ }^{18} \mathrm{~F}\right]$ Selectfluor bis(triflate) 1.

shown to work effectively in contexts where conventional $\left[{ }^{18} \mathrm{~F}\right] \mathrm{F}_{2}$ would generate complex reaction mixtures. Enolate fluorination in the presence of an arene, for example, gave only the desired $\alpha$-fluoro- $\alpha$-methyltetralone, in good yield (Scheme 2). $\left[{ }^{18} \mathrm{~F}\right]$ Selectfluor also proved readily reactive in scenarios where other stable fluorinating agents (e.g., $\left[{ }^{18} \mathrm{~F}\right] \mathrm{N}$ fluorobenzenesulfonimide) were not, such as in the $\mathrm{Ag}^{\mathrm{I}}$ mediated fluorodestannylation of electron-rich aromatic substrates.

Until recently, stable electrophilic ${ }^{18} \mathrm{~F}$ fluorination reagents similar to 1 have exclusively been prepared using highspecific activity $\left[{ }^{18} \mathrm{~F}\right] \mathrm{F}_{2}$. Ritter and co-workers have now reported the preparation of the first electrophilic ${ }^{18} \mathrm{~F}$ fluorination reagent derived from a $\left[{ }^{18} \mathrm{~F}\right]$ fluoride ion, $\mathbf{3}$ (Scheme 3). ${ }^{[5]}$ Treatment of the in situ generated fluorophilic palladium(IV) species 2 with $\left[{ }^{18} \mathrm{~F}\right] \mathrm{KF}$ affords 3 . Following filtration of $\mathbf{3}$ over a polymer-supported resin, $\mathrm{Pd}^{\mathrm{II}}$ aryl complexes such as estrone-derived $\mathbf{4}$ are introduced and warmed at $85^{\circ} \mathrm{C}$ for $10 \mathrm{~min}$ prior to processing. The two-step 
<smiles>COC1=C(C)CCc2ccccc21</smiles>

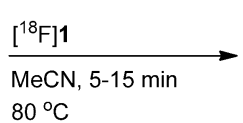<smiles>[R16]c1ccc([AsH2])cc1[R20]</smiles>
Fl1 (excess)<smiles>CC1([18F])CCc2ccccc2C1=O</smiles>
up to $50 \% \mathrm{RCY}$ $\mathrm{SA}=16.4+/-3.9 \mathrm{GBq} / \mu \mathrm{mol}$<smiles>[R20]c1ccc([18F])cc1[R]</smiles>
acetone RT $20 \mathrm{~min}$

$\mathrm{R}^{1}=\mathrm{Me}, \mathrm{R}^{2}=\mathrm{OMe}, \mathrm{R}^{3}=\mathrm{Me} ; \mathrm{RCY}=18 \%(n=3)$ $\mathrm{R}^{1}=\mathrm{Me}, \mathrm{R}^{2}=\mathrm{H}, \mathrm{R}^{3}=\mathrm{Me} ; \mathrm{RCY}=17 \%(n=3)$ $\mathrm{R}^{1}=\mathrm{Bu}, \mathrm{R}^{2}=\mathrm{H}, \mathrm{R}^{3}=\mathrm{H} ; \mathrm{RCY}=14 \%(n=3)$

Scheme 2. Synthetic applications of $\left[{ }^{18} \mathrm{~F}\right]$ Selectfluor bis(triflate) 1.

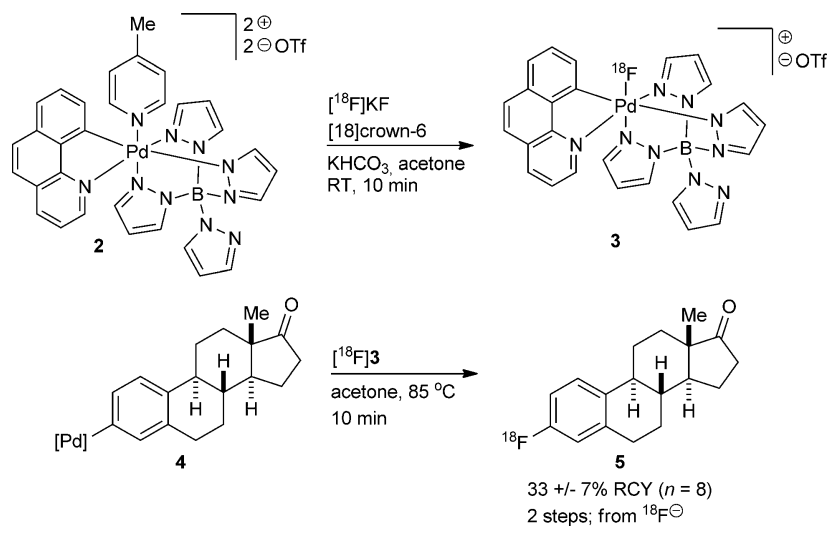

Scheme 3. $\left[{ }^{18} \mathrm{~F}\right]$ Fluoride-derived electrophilic fluorinating reagent, 3 , for PET imaging applications.

${ }^{18} \mathrm{~F}$-labeling processes disclosed generally gave satisfactory radiochemical yields of the target compounds (e.g., 5, Scheme 3). The development of $\mathbf{3}$, given the practicality and wider availability of $\left[{ }^{18} \mathrm{~F}\right] \mathrm{F}^{-}$versus $\left[{ }^{18} \mathrm{~F}\right] \mathrm{F}_{2}$, provides the radiochemist ready access to synthetically useful electrophilic $\left[{ }^{18} \mathrm{~F}\right]$ fluorine.

A number of reports describing improved methods and substrates for nucleophilic fluorination have recently appeared in the literature. Gouverneur and co-workers described a protocol for palladium-catalyzed allylic fluorination $^{[6]}$ that well represents the adaptation of modern synthetic methods for radiochemical synthesis. Allyl 4-nitrophenyl carbonates were smoothly converted to their corresponding allylic fluorides on treatment with $\operatorname{TBAF} \cdot(t \mathrm{BuOH})_{4}$ in the presence of catalytic $\mathrm{Pd}(\mathrm{dba})_{2}(\mathrm{TBAF}=$ tetrabutylammonium fluoride, $\mathrm{dba}=$ dibenzylideneacetone, Scheme 4). The method was then evaluated within the time constraints presented by radionuclide handling. Nitrophenyl cinnamyl carbonate $\mathbf{6}$ gave the corresponding fluoride $\mathbf{7}$ in $7 \%$ radiochemical yield (RCY); higher conversions (10-52\% RCY) were observed using methyl cinnamyl carbonate as substrate under prolonged reaction times $(30 \mathrm{~min})$. Satisfactory yields were also obtained comparing the protocol to direct $\mathrm{S}_{\mathrm{N}} 2$ ${ }^{18} \mathrm{~F}$ fluorination. Subjecting cinnamyl bromide to the system for $5 \mathrm{~min}$ at room temperature gave $20 \% \mathrm{RCY}$ of the corresponding fluoride. Forcing conditions $\left(110^{\circ} \mathrm{C}, 20 \mathrm{~min}\right)$ generated cinnamyl fluoride in 40 and $42 \%$ RCY from

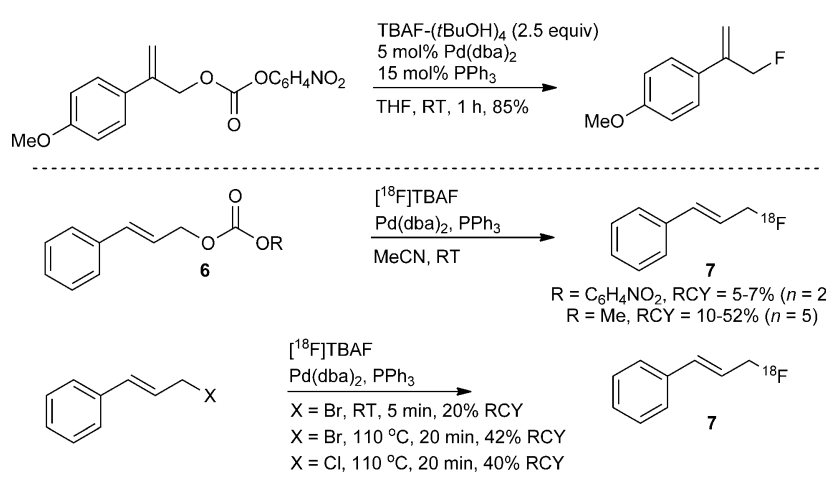

Scheme 4. Pd-catalyzed allylic $\left[{ }^{18} \mathrm{~F}\right]$ fluorination reactions.

cinnamyl chloride and bromide, respectively. Interestingly, products of competitive $\mathrm{S}_{\mathrm{N}} 2^{\prime}$ displacement, which are sometimes evident in direct substitution methods, were not detected in the Pd-mediated variant.

Novel substrates for nucleophilic aromatic substitution $\left(\mathrm{S}_{\mathrm{N}} \mathrm{Ar}\right)$ have recently been a topic of investigation relevant to $\left[{ }^{18} \mathrm{~F}\right]$ fluorination. Symmetric and asymmetric diaryliodonium salts of target precursors, in particular, have received attention owing to their ease of preparation and compatibility with moderately electronic-rich arene systems. ${ }^{[7]}$ For example, Coenen and co-workers have disclosed aryl(2-thienyl)iodonium salts as substrates of ${ }^{18} \mathrm{~F}^{-}$for $\mathrm{S}_{\mathrm{N}}$ Ar which show enhanced reactivity at electron-rich homoarenes (Scheme $5 \mathrm{a}$ ). ${ }^{[8]}$ Sim-

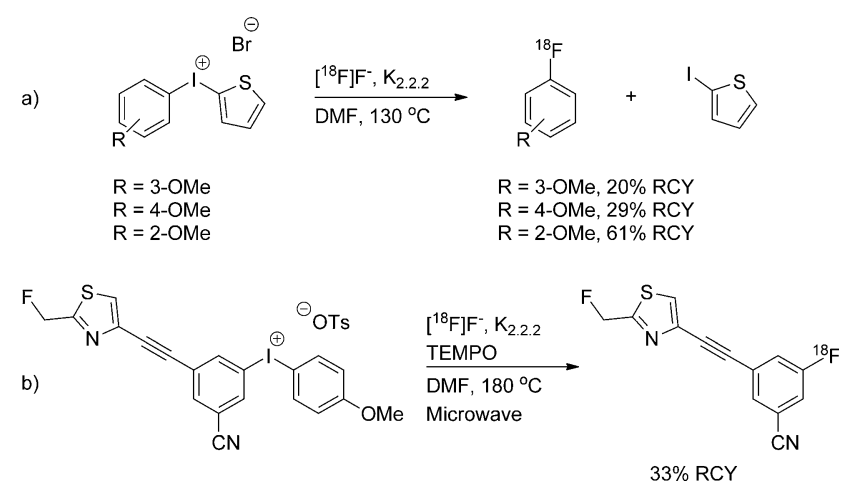

Scheme 5. Diaryliodonium salts for the preparation of $\left[{ }^{18} \mathrm{~F}\right]$ fluoroarenes $\left(\mathrm{K}_{2.2 .2}=\right.$ Kryptofix 2.2.2, TEMPO $=2,2,6,6$-tetramethylpiperidine-1-oxyl).

ilarly, Pike and co-workers have shown the utility of diaryliodonium tosylates in the synthesis of mGluR5 PET radioligands (Scheme 5b). ${ }^{[9]}$ Advances in this area have significantly expanded the scope of classical $\mathrm{S}_{\mathrm{N}} \mathrm{Ar}$ beyond electrondeficient arenes, to the benefit of ${ }^{18} \mathrm{~F}$ radiochemistry.

Direct incorporation of the ${ }^{18} \mathrm{~F}$ radionuclide by either nucleophilic or electrophilic substitution is frequently employed for the preparation of radiopharmaceuticals. Substrates that are not poised for direct ${ }^{18} \mathrm{~F}$ modification, however, are a common hindrance to the synthetic radiochemist. Bimolecular reactions joining reactive ${ }^{18} \mathrm{~F}$-labeled small molecule prosthetic groups with a ligand of interest-or 
"indirect ${ }^{18} \mathrm{~F}$ fluorination"-provide alternative means for accessing radiopharmaceuticals.

$\left[{ }^{18} \mathrm{~F}\right]$ Fluoroazides have found increasing utility as prosthetic groups in ${ }^{18} \mathrm{~F}$ radiochemistry through the azide-alkyne 1,3-dipolar (Huisgen) cycloaddition. ${ }^{[10]}$ Advances in the Huisgen cycloaddition for PET increasingly have had to take into account considerations of intellectual property and the potential for cytotoxic transition-metal contamination in clinic-bound radiotracers. ${ }^{[1]}$ To circumvent the complications presented by copper contamination, Feringa et al. recently described applications of copper-free click chemistry promoted by strained aza-cyclooctynyl species for ${ }^{18} \mathrm{~F}$ radiochemistry ${ }^{[12]}\left[{ }^{18} \mathrm{~F}\right]$ Azide 8 was incubated with azacyclooctyne-modified bombesin 9 (Scheme 6) at ambient temperature for $15 \mathrm{~min}$ (Scheme 5). A satisfactory radiochemical yield was observed in this first example of ${ }^{18} \mathrm{~F}$ radiolabeling through copper-free alkyne-azide [3+2] cycloaddition.

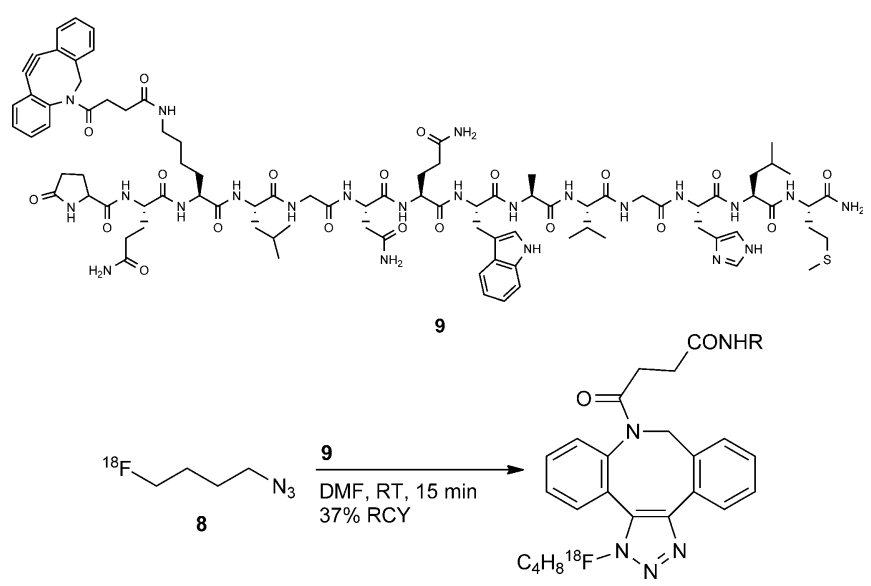

Scheme 6. Representative example of strain relief-promoted, copperfree click chemistry for ${ }^{18} \mathrm{~F}$-radiolabeling. $\mathrm{R}=$ bombesin.

Other innovative $\left[{ }^{18} \mathrm{~F}\right]$ fluorine-containing reagents for radiopharmaceutical preparation have recently been disclosed. Cognizant that the trifluoromethyl is a privileged motif in small molecule drugs, Riss and Aigbirhio reported a technique for the synthesis of $1-\left[{ }^{18} \mathrm{~F}\right]$ fluoro-1,1-difluoromethyl groups. ${ }^{[13]}$ A simple and efficient procedure for the preparation of 2-[ $\left.{ }^{18} \mathrm{~F}\right]$ fluoro-2,2-difluoroethyltosylate $\mathbf{1 1}$ was outlined, beginning from the difluorovinylsulfonate $\mathbf{1 0}$ (Scheme 7). The resulting $\left[{ }^{18} \mathrm{~F}\right]$ fluoroethylating agent proved effective for $\mathrm{O}$ - and $\mathrm{N}$-alkylation, giving rise to the neurofibrillar tangle imaging agent $\mathbf{1 2}$ and the tropane derivative 13, respectively.

Gouverneur and co-workers recently showed that 4$\left[{ }^{18} \mathrm{~F}\right]$ fluorobenzaldehydes are efficient vehicles for ${ }^{18} \mathrm{~F}$ delivery in classical multicomponent reactions. ${ }^{[14]}$ Overcoming substoichiometric quantities of $4-\left[{ }^{18} \mathrm{~F}\right]$ fluorobenzaldehyde $\mathbf{1 4}$ versus other reaction participants and prolonged reaction times witnessed in "cold" studies, radio-Groebke-BienayméBlackburn reactions were successfully executed (Scheme 8). Not illustrated here for the sake of brevity, Ugi, Passerini, and Biginelli reactions were also carried out in good to excellent

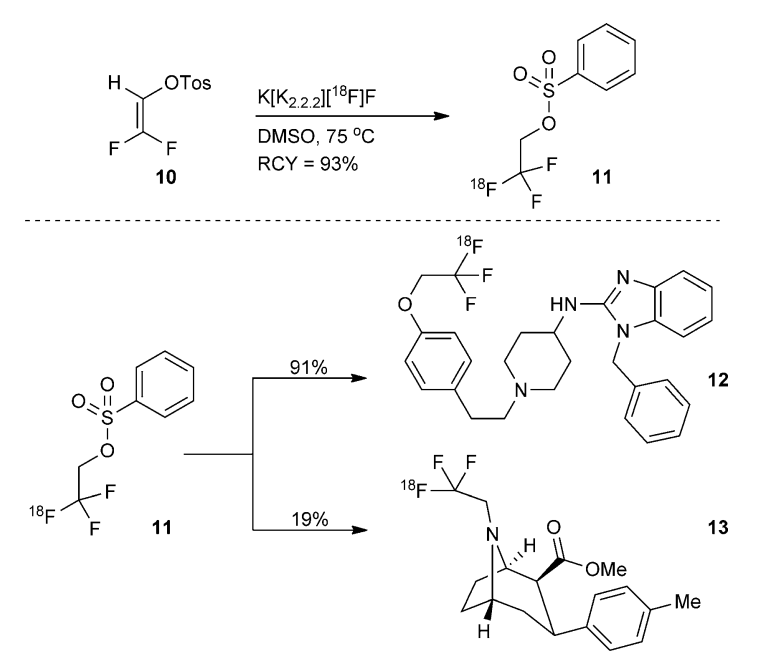

Scheme 7. Preparation and applications of 2-[ $\left.{ }^{18} \mathrm{~F}\right]$ fluoro-2,2-difluoroethyltosylate 11 .

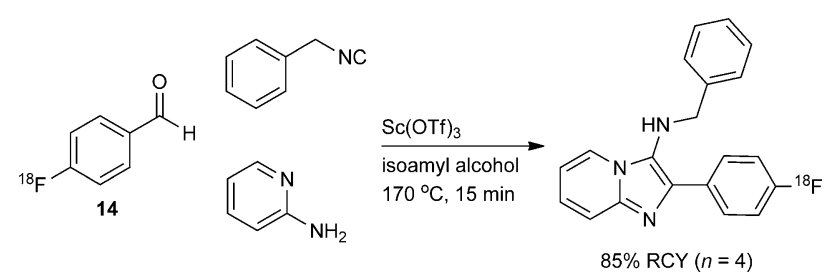

Scheme 8. Radio-Groebke-Bienaymé-Blackburn reaction for the incorporation of $\left[{ }^{18} \mathrm{~F}\right]$ fluorine.

radiochemical yields. Notably, the 3,4-dihydropyrimidin-2(1H)-ones, imidazo[1,2- $a$ ]pyridines and $\alpha$-acyloxyamides obtained by these methods featured ${ }^{18} \mathrm{~F}$ substituents not available by conventional direct $\mathrm{S}_{\mathrm{N}} \mathrm{Ar}$ techniques.

In answer to the increasing demand for novel radiopharmaceuticals, a number of research groups have initiated programs directed toward the development of new radiolabeling methods. This global effort has brought to bear an impressive range of methods and reactions for ${ }^{18} \mathrm{~F}$ radiochemistry. The articles highlighted herein show significant advances in direct electrophilic and nucleophilic fluorination, as well as in the utility of radiolabeled prosthetic groups.

Received: September 24, 2011

Published online: December 23, 2011

[1] For a review, see: P. W. Miller, N. J. Long, R. Vilar, A. D. Gee, Angew. Chem. 2008, 120, 9136; Angew. Chem. Int. Ed. 2008, 47, 8998, and references therein.

[2] Progress in ${ }^{11} \mathrm{C}$ radiochemistry was recently highlighted in the first of these articles: P. J. H. Scott, Angew. Chem. 2009, 121, 6115; Angew. Chem. Int. Ed. 2009, 48, 6001.

[3] H. Teare, E. G. Robins, A. Kirjavainen, S. Forsback, G. Sandford, O. Solin, S. K. Luthra, V. Gouverneur, Angew. Chem. 2010, 122, 6973; Angew. Chem. Int. Ed. 2010, 49, 6821; For other electrophilic ${ }^{18} \mathrm{~F}$ fluorinating agents, see: a) $\left[{ }^{18} \mathrm{~F}\right]$ NFSI: H. Teare, E. G. Robins, E. Arstad, S. K. Luthra, V. Gouverneur, Chem. 
Commun. 2007, 2330-2332; b) $\left[{ }^{18}\right.$ F]AcOF: C.-Y. Shiue, P. A Salvadori, A. P. Wolf, J. S. Fowler, R. R. MacGregor, J. Nucl. Med. 1982, 23, 899, and references therein.

[4] R. E. Banks, S. N. Mohialdin-Khaffaf, G. S. Lal, I. Sharif, R. G Syvret, J. Chem. Soc. Chem. Commun. 1992, 595.

[5] E. Lee, A. S. Kamlet, D. C. Powers, C. N. Neumann, G. B. Boursalian, T. Furuya, D. C. Choi, J. M. Hooker, T. Ritter, Science 2011, 334, 639.

[6] C. Hollingworth, A. Hazari, M. N. Hopkinson, M. Tredwell, E. Benedetto, M. Huiban, A. Gee, J. M. Brown, V. Gouverneur, Angew. Chem. 2011, 123, 2661; Angew. Chem. Int. Ed. 2011, 50, 2613.

[7] a) V. W. Pike, F. I. Aigbirhio, J. Chem. Soc. Chem. Commun. 1995, 2215; b) V. W. Pike, F. I. Aigbirhio, J. Labelled Compd. Radiopharm. 1995, 37, 120; c) R. Gail, C. Hocke, H. H. Coenen, J. Labelled Compd. Radiopharm. 1997, 40, 50; d) A. Shah, V. W. Pike, D. A. Widdowson, J. Chem. Soc. Perkin Trans. 1 1998, 2043; e) J. Ermert, C. Hocke, T. Ludwig, R. Gail, H. H. Coenen, $J$. Labelled Compd. Radiopharm. 2004, 47, 429; f) M. A. Carroll, J. Nairne, G. Smith, D. A. Widdowson, J. Fluorine Chem. 2007, 128, 127.
[8] T. L. Ross, J. Ermert, C. Hocke, H. H. Coenen, J. Am. Chem. Soc. 2007, 129, 8018.

[9] S. Telu, J.-H. Chun, F. G. Siméon, S. Lu, V. W. Pike, Org. Biomol. Chem. 2011, 9, 6629.

[10] The merits of the copper-catalyzed Huisgen cycloaddition (CuAAC) are numerous and have been reviewed extensively in the literature. For a review, see: M. Meldal, C. W. Tornøe, Chem. Rev. 2008, 108, 2952.

[11] For review articles, see: a) M. Glaser, E. G. Robins, J. Labelled Compd. Radiopharm. 2009, 52, 407; b) C. Mamat, T. Ramenda, F. R. Wuest, Mini-Rev. Org. Chem. 2009, 6, 21.

[12] a) L. Campbell-Verduyn, L. Mirfeizi, A. K. Schoonen, R. A. Dierckx, P. H. Elsinga, B. L. Feringa, Angew. Chem. 2011, 123, 11313; Angew. Chem. Int. Ed. 2011, 50, 11117; For seminal reports of copper-free AAC, see: b) G. Wittig, A. Krebs, Chem. Ber. 1961, 94, 3260; c) N. J. Agard, J. A. Prescher, C. R. Bertozzi, J. Am. Chem. Soc. 2004, 126, 15046.

[13] F. I. Aigbirhio, P. J. Riss, Chem. Commun. 2011, 47, 1187311875.

[14] L. Li, M. N. Hopkinson, R. L. Yona, R. Bejot, A. D. Gee, V. Gouverneur, Chem. Sci. 2011, 2, 123. 